\title{
1-Naphthols as components for multifunctional material systems (MFMS): the molecular modeling approach
}

\author{
llona Radkowska ${ }^{1}$ (D) . Piotr Bragiel ${ }^{1}$
}

Received: 3 September 2020 / Accepted: 30 October 2020 / Published online: 24 November 2020

(C) The Author(s) 2020

\begin{abstract}
Increasing research interests have been paid to developing efficient multifunctional material systems (MFMS) by using various composite materials, owing to their useful properties and good stability. Here, we systematically studied 1-naphthols, especially how the type and position of a substituent influence the reactivity and properties, using different electron-directing groups. During computations, important preparation guidelines for thiol derivatives of 1-naphthol were obtained. It is very interesting to note that some molecules could exhibit intramolecular $\mathrm{O}-\mathrm{H}-\mathrm{O}$ interactions. Careful theoretical investigation reveals that all the tested compounds are stable and the molecules with substituents in positions 4 and 8 are the least reactive. It is also worth noting that for the stability and polarizability tensor values, it is more favorable when both substituents are in the same benzene ring. Among tested 1-naphthols, the greatest values of alpha, beta, and gamma are more than 5, 60, and 110 times better respectively, than in the urea molecule; the change of electron-withdrawing group (EWG) to electron-donating group (EDG) increases NLO effects. This study provided a new scope of 1-naphthols applicability by using them as anticorrosion materials and as very good materials for NLO devices due to the high stability of the aromatic structure coupled with polarity given by the substituents. Also, the understanding of IR vibrations for more complex organic compounds with thiol substituent has been improved.
\end{abstract}

Keywords NLO $\cdot$ Substituent effect $\cdot$ DFT $\cdot$ MFMS components $\cdot$ Corrosion inhibition

\section{Introduction}

The composite materials are widely used in different areas of interest [59] including commercial implementations which is related to the possibility of obtaining the extreme properties which cannot be achieved by monolith bulk materials [23]; however, despite their good mechanical properties, they are very similar to other "common" materials acting only as building blocks. Thereby, the concept of introduction of extra functionalities of such materials has been proposed-in this way, materials could be more efficient (e.g., like the addition of self-cleaning property to a

Ilona Radkowska

radkowska.ilona@gmail.com; ilona.radkowska@ujd.edu.pl

1 Faculty of Science and Technology, Jan Dlugosz University, Czestochowa, Poland construction built with a composite material)—through the approach of multifunctional material systems.

Multifunctional material systems (MFMS) are dedicated to exhibit additional functions (as energy accumulation, sensing, and others) apart from their primary functions associated with the mechanical properties as i.e. strength and stiffness $[43,65]$. They are classified into multifunctional materials (MFM), multifunctional composites (MFC), and multifunctional structures (MFS) subgroups. The materials do not request new components, which is realized by combining one or more functional capabilities of constituents already present in the system.

Recently, the multifunctional composite materials have got attention due to their great potential of applications; hence, the research activity in the field is focused on looking for promising components (and functionalities) of such materials. There have been many different concepts proposed, among them the fluid-based actuation systems [14], microchanneled structures for biological usage [52], and composites showing crack surface repairing [62] (more detailed description and examples can be found in [43]). 
Here, we pay attention to 1-naphthols, one of the common groups of organic compounds used in the production of dyes [5, 11, 18, 25, 30, 34, 36, 49, 54] (including the green chemistry approach [6]), which have not been taken into account with regard to becoming the components of composite materials yet.

1-Naphthols are applied in a wide spectrum of interest: from using 2-alkyl-1-naphthol in hair-dyeing [29], through 2-nitroso-1-naphthol spectrophotometric detection of transition metals like ruthenium [32], palladium [13], and cobalt [15] to specific usage of polymers based on 1-naphthols. Especially, the polymerization of 5-amino-1-naphthol [1] is a very interesting aspect of 1-naphthol derivatives due to the corrosion protection possibility and ease of usage because of polyaniline-like structure. It was found that the poly(5amino-1-naphthol) can be applied to form the film, which is semiconducting and exhibits reversible, well-defined oxidation-reduction response in both aqueous solutions of $\mathrm{pH}$ from 1 to 13 and protic non-aqueous solutions [44]. It is also possible to use unsubstituted 1-naphthol to form a polymer exploited as the sensitive, selective electrochemical sensor [35].

Based on their wide spectrum of implementations, it is clearly seen the 1-naphthols could represent quite interesting topic in relation to their potential of usage in MFMS. Besides the above-mentioned concepts of deployment, it is possible to find other functionalities of the group of organic compounds which may improve the properties of composite materials to be used in nonlinear optics (NLO) as materials for laser technology, data storage, and optical communication [58]. However, there is almost no data concerning nonlinear optical properties of any of 1-naphthols (so far the broader studies associated with the research scope have been developed by our group [8]), although they could be a promising object for the NLO field due to the planarity of the system provided by the aromatic ring of naphthalene and the possibility of charge transfer because of the presence of strong electron-donating hydroxyl group in the position 1 of the ring.

The electron transfer process could be also applied in the anti-corrosion treatment of organic molecules since it is based on the transfer of electrons between the studied molecule and structures forming a protected surface [42]. The type of a surface and in particular its charge distribution defining its chemical reactivity determine the properties of a prospective corrosion inhibitor. The question of the study is whether it is possible to obtain a corrosion inhibitor dedicated to the specific surface just by changing substituents in the 1-naphthol ring.

In this paper, some theoretical considerations concerning different substituents, their positions in the 1-naphthol ring, and their influence on different properties are taken into account. The influence of the position and type of the substituent is considered, based on two different substituent types: electron-withdrawing (EWG) and electron-donating (EDG) groups, both having a moderate magnitude of EDG/EWG effect. Here, both types of EDG/EWG groups are studied for all possible positions in the aromatic ring to perform the analysis of their influence on the geometry of the aromatic ring, and determine the relative energies, reactivity descriptors for the prediction of the reactivity of each type of compound and substituent position. In this way, some predictions concerning an ability of corrosion protection and other applications associated with reactivity are performed. The final task is to calculate the values of polarizability and hyperpolarizability tensors to determine the potential of the 1-naphthol derivatives in the NLO field and to select the most promising molecule for usage in NLO applications. All the calculations are performed in APF-D hybrid functional having dispersion functions and NLO-V basis set.

\section{Computational details}

Computational analysis of different 1-naphthol derivatives presented in Fig. 1 was performed in Gaussian 16.A03 [20] package using APF-D [4] functional-which is similar to B3LYP hybrid functional, however is improved through dispersion treatment - and NLO-V basis set [47], dedicated especially for NLO calculations. All the calculations were made both for neutral and ionic forms of each molecule in vacuum to avoid any influence from a medium in which a molecule could be put. In the calculations, the highest possible symmetry of each molecule is considered the presence of imaginary frequency disqualifies proposed symmetry and the lower point group is then considered. Hence, for naphthalene $(\mathbf{N}) \mathrm{D}_{2 h}$ point group is analyzed, for 1-naphthol (1N) and all its aldehyde derivatives (nA1N) (the exceptions are compounds with the position of 6 and 8 $-\mathrm{C}_{1}$ point group) $\mathrm{C}_{s}$ point group is considered, for all thio (nSH1N) and ester (nE1N) derivatives of 1-naphthol the $\mathrm{C}_{1}$ point group is proposed. The reactivity descriptors were calculated on the basis of natural bond orbital population analysis for optimized structures using the same calculation method as in the optimization process, using the NBO 3.1 program [22].

Global hardness $(\eta)$ and global softness $(S)$ were calculated (and analyzed) as it was indicated in [46, 60, 61, 66]:

$\begin{aligned} \eta & =\frac{I-A}{2} \\ S & =\frac{1}{\eta}\end{aligned}$

where $I$ is the ionization potential and $A$ is the electron affinity. 


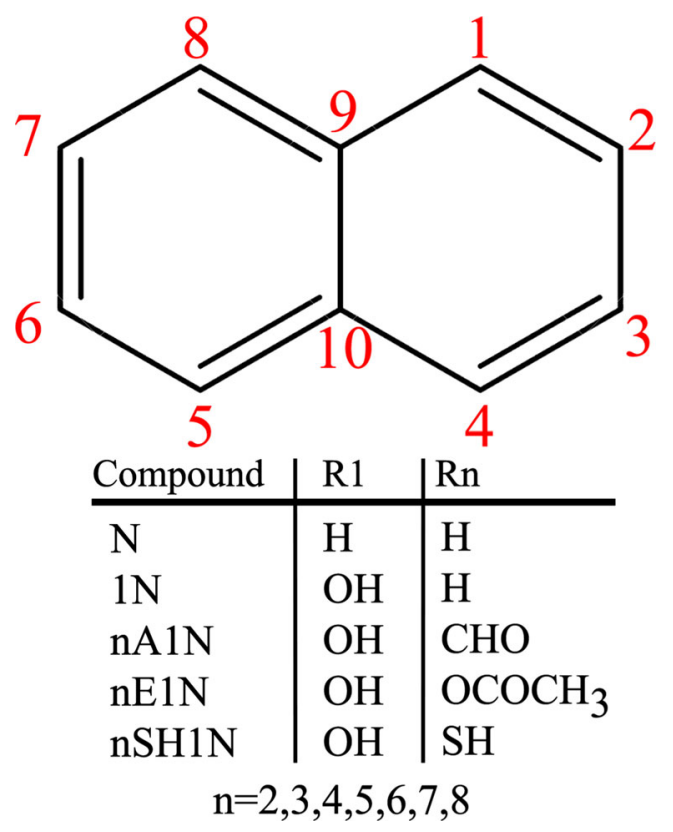

Fig. 1 The schematic figure of all studied bi-substituted molecules; $\mathrm{R}$ with number denotes the substituent is attached in the position indicated with the number, e.g., for the $4 \mathrm{E} 1 \mathrm{~N}$ the $\mathrm{n}$ is equal to 4 and $\mathrm{R} 4$ stands for $\mathrm{OCOCH}_{3}$ in the position 4 of the ring; in all the positions, except the specific $n$, there are hydrogen atoms

$I$ and $A$ descriptors (their definitions can be found in $[28,39]$ respectively) were calculated from the energies of neutral and ionic forms of each studied molecule instead of simplified calculations based on HOMO-LUMO energies due to the fact that for almost all of the commonly used exchange-correlation functionals, the negative of the HOMO energy is not close to the exact ionization potential and can be used only to semiquantitatively estimate the ionization potential, electron affinity, electronegativity, hardness, and first excitation energy [67].

Electronegativity $(\chi)$ and electrophilicity $(\omega)$ (according to information shown in $[48,57,61]$ ) were calculated using the formulas presented in [12]:

$\chi=\frac{I+A}{2}$

$\omega=\frac{\chi^{2}}{2 \eta}$

In the case of local reactivity descriptors, for each atom in the molecule, two different basic reactivity indexes were used: Fukui functions and local softness.

It was showed $[21,26]$ that the greatest values of the Fukui functions are associated with the greatest reactivity sites of the molecule. To predict the behavior of the molecule for electrophilic attack, it is necessary to use $f^{-}$ Fukui function, for nucleophilic attack one needs to use $f^{+}$Fukui function [21], while for the radical attack the $f^{0}$
Fukui function should be used [37]. The Fukui functions were calculated using the following formulas [16]:

$f_{k}^{+}=q_{k}(N+1)-q_{k}(N)$

$f_{k}^{-}=q_{k}(N)-q_{k}(N-1)$

$f_{k}^{0}=\frac{q_{k}(N+1)-q_{k}(N-1)}{2}$

where $N$ is the number of electrons in ground-state geometry of neutral system [37]; $q_{k}$ is the charge on $k$-th atom.

Additionally, a dual descriptor, $\Delta f_{k}$, was calculated as the index of selectivity toward both nucleophilic and electrophilic attacks. It is defined as in [41]:

$\Delta f_{k}=f_{k}^{+}-f_{k}^{-}$

If $\Delta f_{k}>0$, then the site is favored for a nucleophilic attack, whereas if $\Delta f_{k}<0$, then the site could be favored for an electrophilic attack [41].

To obtain relative electrophilicity $\left(s_{k}^{+} / s_{k}^{-}\right.$; to facilitate the notation, the subscripts in all local descriptors will be omitted, thereby it will be written as $s^{+} / s^{-}$) and nucleophilicity $\left(s_{k}^{-} / s_{k}^{+}\right)$(further written as $\left.s^{-} / s^{+}\right)$descriptors, the local softness has to be calculated. The local softness will not be studied here itself because of the well-known fact that the local softness contains the same information as the Fukui functions [51]. The formulas for $s_{k}^{+}, s_{k}^{-}$are calculated, multiplying appropriate Fukui functions per global softness [51].

Additionally, in the similar way as in the case of Fukui functions (see Eq. 8), the $\Delta s_{k}$ was calculated as in [41]:

$\Delta s_{k}=S\left(f_{k}^{+}-f_{k}^{-}\right)=s_{k}^{+}-s_{k}^{-}$

In the case of NLO properties, the dipole moments $(\mu)$, polarizability $(\alpha)$, and first- $(\beta)$ and second- $(\gamma)$ order hyperpolarizability tensors were considered. The nonlinear optical properties were analyzed for the static and dynamic, $532-\mathrm{nm}$ wavelength, cases. The obtained values were calculated according to the following formulas [10, 24]:

$$
\begin{aligned}
\alpha & =\frac{\alpha_{x x}+\alpha_{y y}+\alpha_{z z}}{3} \\
\beta & =\sqrt{\beta_{x}^{2}+\beta_{y}^{2}+\beta_{z}^{2}} \\
\beta_{x} & =\beta_{x x x}+\beta_{x y y}+\beta_{x z z} \\
\beta_{y} & =\beta_{y y y}+\beta_{x x y}+\beta_{y z z} \\
\beta_{z} & =\beta_{z z z}+\beta_{x x z}+\beta_{y y z} \\
\gamma & =\frac{\gamma_{x x x x}+\gamma_{y y y y}+\gamma_{z z z z}+2\left(\gamma_{x x y y}+\gamma_{x x z z}+\gamma_{y y z z}\right)}{5}
\end{aligned}
$$

The calculated values are then compared with reference material. The urea molecule is used as the fundamental NLO 
reference material [31]. The comparison could be done due to the asseveration of the same conditions of calculations. The urea molecule symmetry was chosen as $C_{2}$ as the most stable [56].

\section{Results and discussion}

As the basis of further work, it is necessary to study structural properties of isomeric molecules differing in substituent place in the naphthalene ring and their potential of usage in relation to certain properties. For this aim, two representatives of different electron-directing groups were chosen both exhibiting moderate electron directing effect to analyze its average influence on the properties of the molecules. As EWG the aldehyde group and as EDG the thio and ester groups were chosen (as it is presented in Fig. 1). The choice of two EDGs was dictated by some problems with geometry optimization of the thio derivatives in positions $2,3,7$, and 8 . We assumed the electrons from the thio group are too close to the hydroxyl group and their repulsion is the case of a problem with the geometry optimization procedure. Hence, a little more extensive substituent was studied-the substituent from the simplest ester: as the $\mathrm{R}$ group, the methyl group was chosen.

\section{Optimized structures}

All studied molecules' geometries were optimized for the highest possible symmetry of each molecule at the ground state. In Table S1 in Supplementary Information (SI), there are structural parameters associated with aromatic ring bond lengths and valence angles and the values of the bonds between the aromatic carbon atom and oxygen atom from hydroxyl group (C-O) and between the aromatic carbon atom and first atom of the substituent (C-subst), in relation to corresponding parameters of naphthalene ring (N compound) and unsubstituted 1-naphthol molecule (1N compound).

As it can be seen from Table S1, deviations from N/1N molecules for all the compounds are quite small, differing less than $0.035 \AA$ in the case of maximal deviations and $0.002 \AA$ in the case of average deviations. Greater deviations are observed for the angles: while average deviations are $0.36 / 0.35^{\circ}$ in relation to $\mathrm{N} / 1 \mathrm{~N}$ molecules respectively, the maximal deviations are $4.5^{\circ}$. As expected, better geometry accordance is found in relation to $1 \mathrm{~N}$ molecule than $\mathrm{N}$. Among all studied compounds, $3 \mathrm{~A} 1 \mathrm{~N}$ and $5 \mathrm{E} 1 \mathrm{~N}$ have the geometric parameters the most similar to unsubstituted molecules; on the other hand, thio compounds have the least similar geometry, which could be taken as the confirmation of strong repulsion between both substituents distorting the shape of the naphthalene ring.
It is known for the naphthalene case that EDG directs new substituent to the same benzene ring (having 1-4, 910 positions numeration, as shown in Fig. 1) of naphthalene whereas EWG causes substitution in the other benzene ring (atoms with numbers 5-10), thereby for hydroxyl group, which is highly EDG, and another EDG (like ester substituent), the most probable positions for bonds are 2 and 4 (very similar probability of both positions) due to the ortho- and para-substitution - the effect is enhanced by the presence of two EDG groups-the positions indicated by EWG are the least probable; hence, the bonds formed there (positions 6 and 8) are the weakest (longest). Here, positions 3 and 7 are similarly probable due to the same, quite small, distance from the $\mathrm{OH}$ group and are comparably influenced by its presence. For the position 5, electron charges are dispersed almost symmetrically (some differences could result from substituent type and its directing effect magnitude): as a result, the bond formed here should not be strong.

A quite different situation is observed when EWG is used as the second substituent group. We assume there is a possibility of some influence from the interaction between partially negative-charged $\mathrm{OH}$ group and partially positivecharged EWG. Due to the high magnitude of the EDG effect, the influence of the hydroxyl group would be greater than the EWG group, and the observed order of bond lengths is similar to the case of both EDG groups (the extreme positions: $8,5,2$ ). The lengths of the other bonds are reversed in relation to the case of the two EDGs.

A more detailed description can be found in Supplementary Information (SI).

\section{Energy}

In Table S2, there are presented energetic relations presented between all studied molecules differing in substituent position.

For studied EWG, the most stable is the compound with the substituent at position 3 (what is shown in Fig. 2). However, the following three energetically stable compounds $(2 \mathrm{~A} 1 \mathrm{~N}, 6 \mathrm{~A} 1 \mathrm{~N}, 7 \mathrm{~A} 1 \mathrm{~N})$ should be almost equally probable at room temperature because the energy difference is less than $1 \mathrm{kcal} / \mathrm{mol}$. The least energetic stable is $8 \mathrm{~A} 1 \mathrm{~N}$ (more than $6 \mathrm{kcal} / \mathrm{mol}$ in relation to the $3 \mathrm{~A} 1 \mathrm{~N}$ ). The energy order of the compounds is as follows:

$8 \mathrm{~A}>5 \mathrm{~A}>4 \mathrm{~A}>7 \mathrm{~A}>2 \mathrm{~A}>6 \mathrm{~A}>3 \mathrm{~A}$

The high energy of compound having the substituent at the position 8 is obvious; in its geometry, the substituent is partially perpendicular to the plane of the 1-naphthol (as can be seen in Fig. S1), which is highly energetically non-preferable (the same type of geometry is observed for $6 \mathrm{E} 1 \mathrm{~N}$ molecule). The rest of the molecules is ordered symmetrically (the substituent positions 5 and 4, 7 and 2, 
6 and 3) and the structure, in which both substituents are localized at the same benzene ring, has lower energy.

The energy of the compound having two EDG groups ( $\mathrm{OH}$ and ester groups) is the lowest for 2E1N (see Fig. 2) and $7 \mathrm{E} 1 \mathrm{~N}$. The molecules could probably form O-H-O interaction between the hydroxyl group and oxygen atom from the ester group, which significantly minimizes energy (for 7E1N the formation of interaction is more difficult due to the necessity of engaging almost the whole molecule) in relation to the other molecules with the substituent (the energies are greater than $11 \mathrm{kcal} / \mathrm{mol}$ in relation to $2 \mathrm{E} 1 \mathrm{~N})$. The highest energy is found for $6 \mathrm{E} 1 \mathrm{~N}$ due to its geometry (as it was analyzed previously, see Fig. S1). Here, also the order of the molecules due to their symmetrical relations (as in the case of the EWG substituent) is preserved; thereby, 3E1N is the second-highest energy molecule. Then, molecules having perpendicular substituent orientation $(8 \mathrm{E} 1 \mathrm{~N}$ and $5 \mathrm{E} 1 \mathrm{~N})$ are next. As in the case of EWG, among symmetric positions, energetically preferred are the positions in which both substituents are present in the same benzene ring. Only two pairs $(5 \mathrm{E} 1 \mathrm{~N}-8 \mathrm{E} 1 \mathrm{~N}$ and $3 \mathrm{E} 1 \mathrm{~N}-$ $6 \mathrm{E} 1 \mathrm{~N}$ ) have comparable energies and could be present at equilibrium at room temperature. The energy sequence of the compounds is as follows:

$6 \mathrm{E}>3 \mathrm{E}>8 \mathrm{E}>5 \mathrm{E}>4 \mathrm{E}>7 \mathrm{E}>2 \mathrm{E}$

\section{IR spectra}

The infrared spectra of all studied 1-naphthol derivatives are simulated. Additionally, the analysis of IR frequencies having intensities more than $5 \mathrm{M}^{-1} \mathrm{~cm}^{-1}$ was performed using the GaussView program. Due to the lack of scaling factors for the method and basis set and any experimental spectra (to scale the calculated values to the most intense peaks), the presented values are shown as pure data from

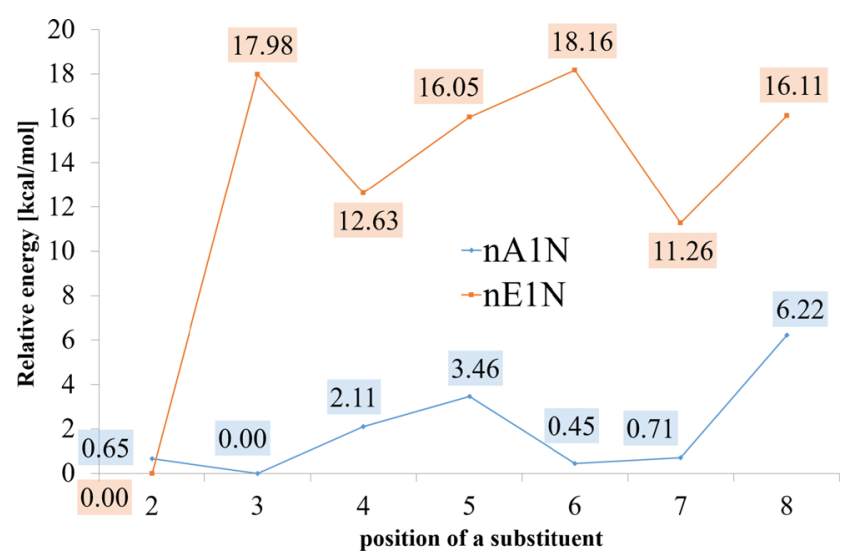

Fig. 2 Analysis of relative energetic relations between different 1-naphthol derivatives for studied EWG and EDG in relation to substituent position in naphthalene ring calculations. For all the simulated spectra (Fig. S2), there is performed a detailed analysis of vibrations divided into the aromatic ring and substituent vibrations (Table S3) and type of modes (Table S4). Additionally, there are presented the vibrations of the SH group which improve the knowledge about more complex organic molecules with thio substituents (than simply thiol-substituted aliphatic hydrocarbons [40]) not studied theoretically in detail yet.

The exemplary IR spectrum for $6 \mathrm{E} 1 \mathrm{~N}$ is presented in Fig. 3. The vibrations of the $\mathrm{OH}$ group are localized near 3750 and $250 \mathrm{~cm}^{-1}$ (for ester substituents there is an additional $\mathrm{OH}$ peak around $1250 \mathrm{~cm}^{-1}$ ). The vibrations of the substituent can be analyzed as $\mathrm{C}-\mathrm{H}$ vibrations, $\mathrm{C}-\mathrm{O}$ vibrations, and $\mathrm{SH}$ vibrations. For both substituents having $\mathrm{C}, \mathrm{H}$, and $\mathrm{O}$ atoms, the vibrations of $\mathrm{C}-\mathrm{H}$ can be found near 1500 and $3000 \mathrm{~cm}^{-1}$ (for $\mathrm{nE} 1 \mathrm{~N}$ molecules, there are additional peaks as shown in Tables S3 and S4) and for C$\mathrm{O}$, the vibrations around $1915 \mathrm{~cm}^{-1}$. The vibrations of the SH group are found at about 1300, 2300, and $6780 \mathrm{~cm}^{-1}$. All the values are in accordance with experimental data: $\mathrm{OH}$ around $3610 \mathrm{~cm}^{-1}$, phenolic $\mathrm{C}-\mathrm{O}$ around $1260 \mathrm{~cm}^{-1}$, $\mathrm{C}-\mathrm{H}$ in methyl group around $3000 \mathrm{~cm}^{-1}, \mathrm{C}-\mathrm{C}$ benzene ring vibrations in the ranges: $1585-1600$ and 1400 $1500 \mathrm{~cm}^{-1}$ [3] and $\mathrm{SH}$ vibrations in the range greater than $5000 \mathrm{~cm}^{-1}[40]$.

\section{Selected property analysis}

\section{Reactivity}

Reactivity has a crucial role in chemistry because of its association with reaction mechanisms, thereby it allows understanding and describing chemical reactions that is a very important task in improving synthesis procedures to obtain new materials [7]. In Table 1, the global reactivity descriptors are presented; and in Table 2, the selected local reactivity descriptors are listed. More detailed data can be found in Tables S5, S6 (the global reactivity descriptors of

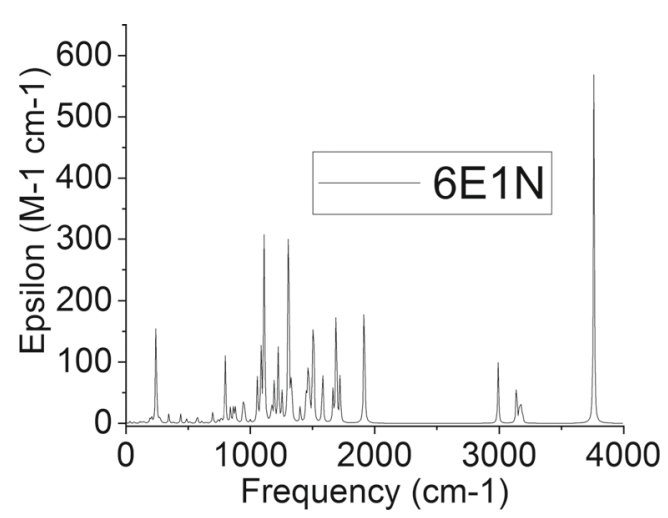

Fig. 3 Simulated IR spectrum of $6 \mathrm{E} 1 \mathrm{~N}$ molecule 
Table 1 The selected reactivity descriptors calculated from the energies of neutral and ionic forms of each molecule; values expressed in eV (only in the case of $\mathrm{S}$ the values are in $\mathrm{eV}^{-1}$ ); for more details, see "Computational details" section

\begin{tabular}{|c|c|c|c|c|c|c|c|c|c|}
\hline Compound & HOMO & LUMO & $\Delta$ & I & A & $\eta$ & $\chi$ & $\omega$ & $\mathrm{S}$ \\
\hline $\mathrm{N}$ & -6.74788 & -1.72221 & 5.026 & 8.520 & -0.019 & 4.269 & 4.251 & 2.116 & 0.234 \\
\hline $1 \mathrm{~N}$ & -6.13372 & -1.40955 & 4.724 & 7.897 & -0.312 & 4.105 & 3.792 & 1.752 & 0.244 \\
\hline $4 \mathrm{~A} 1 \mathrm{~N}$ & -6.38815 & -1.95242 & 4.436 & 8.069 & 0.308 & 3.880 & 4.188 & 2.260 & 0.258 \\
\hline $5 \mathrm{~A} 1 \mathrm{~N}$ & -6.33998 & -2.12875 & 4.211 & 8.048 & 0.463 & 3.792 & 4.256 & 2.388 & 0.264 \\
\hline 4SH1N & -6.09971 & -1.67568 & 4.424 & 7.801 & 0.016 & 3.893 & 3.908 & 1.962 & 0.257 \\
\hline $5 \mathrm{SH} 1 \mathrm{~N}$ & -6.18706 & -1.64357 & 4.543 & 7.873 & -0.010 & 3.942 & 3.932 & 1.961 & 0.254 \\
\hline $4 \mathrm{E} 1 \mathrm{~N}$ & -6.23576 & -1.58806 & 4.648 & 7.879 & -0.018 & 3.948 & 3.931 & 1.957 & 0.253 \\
\hline $5 \mathrm{E} 1 \mathrm{~N}$ & -6.30951 & -1.68330 & 4.626 & 7.975 & 0.054 & 3.961 & 4.014 & 2.034 & 0.252 \\
\hline
\end{tabular}

all studied molecules and the analysis of the reactivity order for each studied substituent position), S7 (the list of atoms, for which $f^{+}$Fukui functions are dominating), S8 (the list of atoms, for which $f^{-}$Fukui functions are dominating), S9 (the list of atoms, for which $s^{+} / s^{-}$electrophilicity descriptor has major influence), S10 (the list of atoms, for which $s^{-} / s^{+}$nucleophilicity descriptor is dominating), and $\mathrm{S} 11$ (the analysis of $\Delta f$ and $\Delta s$ dual descriptors) in Supplementary Information, as well as a more detailed description of the reactivity of naphthalene and 1-naphthol molecules.

Frontier orbitals The most important orbitals in a molecule are labeled the frontier orbitals: HOMO (highest occupied molecular orbital) and LUMO (lowest unoccupied molecular orbital). The orbitals are strictly associated with molecule ability to donate (HOMO) and accept (LUMO) an electron; thereby, the frontier orbitals are directly related to ionization potential and electron affinity respectively [57].
The energy band gap associated with energy charge transport is calculated in the form of the energy difference between HOMO and LUMO orbitals as the analogs of the valence and conduction bands, respectively [17]. The HOMO-LUMO energy gap is generally the electronic excitation energy in a molecule having possibly the lowest energy [63]. It is obvious the large value of the HOMOLUMO energy gap implies high kinetic stability and low chemical reactivity [2] due to the hindered electron possibility to transfer to LUMO level from distant HOMO level. It was found in [17] that the band gap energy decreases progressively with the number of benzene rings (the experimental data of $\mathrm{E}_{\text {gap }}(\mathrm{eV})$ was derived for a few aromatic hydrocarbons: naphthalene (4.14), anthracene (3.20), tetracene (2.54), and rubrene (2.20)). Values calculated for the naphthalene confirmed it is a very stable compound [2].

According to data collected in Tables 1 and S5, the obtained values of $\mathrm{E}_{\text {gap }}$ are in the range between 4.21 $(5 \mathrm{~A} 1 \mathrm{~N})$ and $5.03(\mathrm{~N}) \mathrm{eV}$ which indicates tested compounds
Table 2 The most reactive places of studied compounds using different local descriptors: Fukui functions $\left(f^{+}, f^{-}, f^{0}\right)$, relative electrophilicity $\left(s^{+} / s^{-}\right)$and nucleophilicity $\left(s^{-} / s^{+}\right), \Delta f$ and $\Delta s$ dual descriptors; the atom numeration in accordance with Fig. 1; in ester substituent carbon atoms are numbered as E1 (carboxyl substituent) and E2 (methyl substituent); hydrogen atoms are listed as $\mathrm{H}$-carbon atom number, e.g., $\mathrm{H} 7$ means hydrogen atom associated with $\mathrm{C} 7$ of the naphthalene ring

\begin{tabular}{llllllll}
\hline Compound & $\mathrm{f}^{+}$ & $\mathrm{f}^{-}$ & $\mathrm{f}^{0}$ & $\frac{s^{+}}{s^{-}}$ & $\frac{s^{-}}{s^{+}}$ & $\Delta f$ & $\Delta s$ \\
\hline $\mathrm{N}$ & $2,3,6,7$ & $\mathrm{H} 1, \mathrm{H} 4, \mathrm{H} 5, \mathrm{H} 8$ & 9,10 & 9,10 & $1,4,5,8$ & $2,3,6,7$ & $2,3,6,7$ \\
$1 \mathrm{~N}$ & 2 & $H^{O H}$ & 10 & 1 & 5 & 2 & 2 \\
$2 \mathrm{~A} 1 \mathrm{~N}$ & 7 & $H^{O H}$ & 10 & $O^{C H O}$ & 8 & 4 & 4 \\
$3 \mathrm{~A} 1 \mathrm{~N}$ & 2 & $\mathrm{H}^{O H}$ & 10 & 1 & 4 & 2 & 2 \\
$4 \mathrm{~A} 1 \mathrm{~N}$ & 2 & $H^{O H}$ & 10 & 1 & $O^{C H O}$ & 2 & 2 \\
$5 \mathrm{~A} 1 \mathrm{~N}$ & 2 & $\mathrm{H}^{O H}$ & 10 & 1 & 6 & 2 & 2 \\
$6 \mathrm{~A} 1 \mathrm{~N}$ & 7 & $\mathrm{H}^{O H}$ & 10 & 1 & 6 & $O^{O H}$ & $O^{O H}$ \\
$7 \mathrm{~A} 1 \mathrm{~N}$ & 2 & $\mathrm{H}^{O H}$ & 9 & 1 & 5 & 2 & 2 \\
$8 \mathrm{~A} 1 \mathrm{~N}$ & $O^{O H}$ & $\mathrm{H}^{O H}$ & 10 & 1 & $O^{C H O}$ & 2 & 2 \\
$2 \mathrm{E} 1 \mathrm{~N}$ & $\mathrm{E} 2$ & $\mathrm{E} 1$ & 10 & 6 & $O^{E 1}$ & $\mathrm{E} 2$ & $\mathrm{E} 2$ \\
$3 \mathrm{E} 1 \mathrm{~N}$ & $\mathrm{E} 2$ & $\mathrm{E} 1$ & 10 & 1 & 4 & $\mathrm{E} 2$ & $\mathrm{E} 2$ \\
$4 \mathrm{E} 1 \mathrm{~N}$ & $\mathrm{E} 2$ & $\mathrm{E} 1$ & 10 & 1 & 4 & $\mathrm{E} 2$ & $\mathrm{E} 2$ \\
$5 \mathrm{E} 1 \mathrm{~N}$ & $\mathrm{E} 2$ & $\mathrm{E} 1$ & 10 & 1 & 4 & $\mathrm{E} 2$ & $\mathrm{E} 2$ \\
$6 \mathrm{E} 1 \mathrm{~N}$ & $\mathrm{E} 2$ & $\mathrm{E} 1$ & 10 & 1 & 8 & $\mathrm{E} 2$ & $\mathrm{E} 2$ \\
$7 \mathrm{E} 1 \mathrm{~N}$ & $\mathrm{E} 2$ & $\mathrm{E} 1$ & 9 & 1 & 5 & $\mathrm{E} 2$ & $\mathrm{E} 2$ \\
$8 \mathrm{E} 1 \mathrm{~N}$ & $\mathrm{E} 2$ & $H^{O H}$ & 10 & 1 & 5 & $\mathrm{E} 2$ & $\mathrm{E} 2$ \\
\hline
\end{tabular}


can be classified as hard molecules due to the large values of energy gap [19]. It is clearly seen among studied compounds that the most symmetric and aromatic molecule — naphthalene - has the highest value of band gap; the presence of the single substituent ( $\mathrm{OH}$ group) in $1 \mathrm{~N}$ causes a drop in the value of band gap confirming the substituent influence on $\pi$-electron delocalization in the aromatic ring (the influence is weak [27], about $0.3 \mathrm{eV}$ ) and greater reactivity of 1-naphthol over naphthalene [9]. All tested 1-naphthol derivatives should exhibit high stability. However, for the same substitution position, higher values of $\mathrm{E}_{\text {gap }}$ have molecules with EDG rather than EWG, as presented in Table 4 and Fig. 4. Especially high differences of reactivity are found for the ortho and para positions in the second benzene ring, whereas $\mathrm{E}_{\text {gap }}$ for the position 4 is not influenced by the type of electron-directing group and is the most stable position in the ring. The order of stability is as follows:

$$
\begin{aligned}
& 4 \mathrm{~A}>2 \mathrm{~A}>3 \mathrm{~A}>8 \mathrm{~A}>6 \mathrm{~A}>7 \mathrm{~A}>5 \mathrm{~A} \\
& 4 \mathrm{E}>8 \mathrm{E}>5 \mathrm{E}>3 \mathrm{E}>6 \mathrm{E}>7 \mathrm{E}>2 \mathrm{E}
\end{aligned}
$$

HOMO orbital is related to the sites of prospective electrophilic attack and LUMO is linked with the nucleophilic attack site [26]. In Fig. 5, the exemplary HOMO and LUMO orbitals are presented (the frontier orbitals of $\mathrm{N}, 1 \mathrm{~N}$, and all tested $1 \mathrm{~N}$ derivatives are shown in Fig. S1a). The positive phases are the red regions whereas the negative phases are green regions [63].

Despite the type of tested derivatives, the HOMO orbital is localized in the region of the carbonyl group of the substituent, with the main influence from the carbonylic oxygen atom, and the LUMO orbital is localized mainly in the region of the $\mathrm{C} 1, \mathrm{C} 2$ atoms with small influence from surrounding (C3 and C9) atoms. When there is no carbonyl substituent (as in the case of $1 \mathrm{~N}$ and thio derivatives),

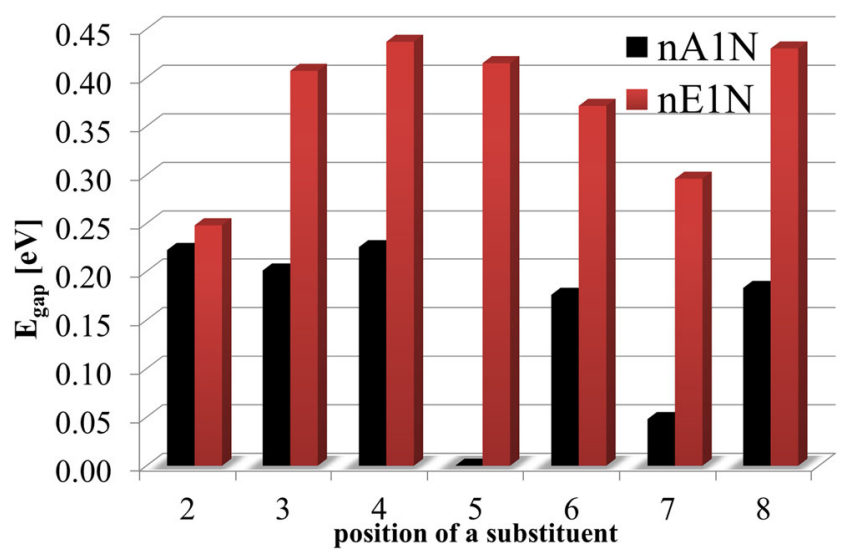

Fig. 4 The analysis of $\mathrm{E}_{\text {gap }}$ of studied compounds in relation to a substituent position; the $5 \mathrm{~A} 1 \mathrm{~N}$ (as having the minimal value) is used as the reference the HOMO orbital has the same localization as in the unsubstituted naphthalene molecule.

MEP Molecular electrostatic potential (MEP) surface is used to visualize variable charged regions of a molecule with colors associated with different electrostatic potential values: red (represents the regions of most electronegative electrostatic potential-electron-rich places [55]), blue (as the most positive electrostatic potential-electron-deficient places), and green (as zero potential-neutral places). The potential decreases in the order: blue $>$ green $>$ yellow $>$ orange $>$ red [57]. MEP can be useful to analyze the polarization and charge transfer effects within molecules [55], their molecular structures, physico-chemical property relationships, and the interactions between studied molecules by showing the shape, size, charge density, and site of chemical reactivity of the molecules [57].

The addition of the EWG group generally causes charge transfer from the hydroxyl group through the naphthalene ring to the aldehyde group (as can be seen in Fig. S1b). When both substituents are attached to the same benzene ring $(2 \mathrm{~A} 1 \mathrm{~N}, 3 \mathrm{~A} 1 \mathrm{~N}$, and $4 \mathrm{~A} 1 \mathrm{~N})$, the charge transfer is smaller than in the case in which electrons have to flow through both benzene rings $(5 \mathrm{~A} 1 \mathrm{~N}, 6 \mathrm{~A} 1 \mathrm{~N}, 7 \mathrm{~A} 1 \mathrm{~N}$, and $8 \mathrm{~A} 1 \mathrm{~N}$ ) to find oxygen atom from the $\mathrm{CHO}$ group. The least reactive structure is $4 \mathrm{~A} 1 \mathrm{~N}$ in which substituents are in the para position in relation to the benzene ring-the electrons are scattered within the almost whole molecule. On the other hand, the most reactive structure is $8 \mathrm{~A} 1 \mathrm{~N}$ - the electrons move through all the molecules to accumulate at the oxygen atom of the aldehyde group. The reactivity of the 1naphthols with aldehyde group in the second benzene ring is as follows: $5 \mathrm{~A} 1 \mathrm{~N}<6 \mathrm{~A} 1 \mathrm{~N}<7 \mathrm{~A} 1 \mathrm{~N}<8 \mathrm{~A} 1 \mathrm{~N}$, which is indicated by increasing electron-rich character (yellow color of MEP) of the region near the oxygen atom from the aldehyde group. The situation in $5 \mathrm{~A} 1 \mathrm{~N}$ and $6 \mathrm{~A} 1 \mathrm{~N}$ is quite similar to 1-naphthols with both substituents in the same benzene ring (see $2 \mathrm{~A} 1 \mathrm{~N}$ and $3 \mathrm{~A} 1 \mathrm{~N}$ in Fig. S1b) with a slightly greater electronegative potential of the aromatic ring; in $6 \mathrm{~A} 1 \mathrm{~N}$, the contribution of electron-rich regions near the oxygen atom is greater than that in $5 \mathrm{~A} 1 \mathrm{~N}$. The most reactive are $7 \mathrm{~A} 1 \mathrm{~N}$ and $8 \mathrm{~A} 1 \mathrm{~N}$ molecules in which there is a possibility of forming $\mathrm{O}-\mathrm{H}-\mathrm{O}$ weak interactions (as it is presented by the example of $7 \mathrm{E} 1 \mathrm{~N}$ in Fig. 6; the analogous situations can be observed in $2 \mathrm{E} 1 \mathrm{~N}, 3 \mathrm{E} 1 \mathrm{~N}$, and $7 \mathrm{E} 1 \mathrm{~N}$ molecules) stronger in $8 \mathrm{~A} 1 \mathrm{~N}$ due to the proximity of both oppositely charged substituents separating charges (in $8 \mathrm{~A} 1 \mathrm{~N}$ the contribution of yellow-as slightly electronegative place indicator-is the greatest among all $\mathrm{nA} 1 \mathrm{~N}$ molecules and is deployed continuously from the aromatic ring to the oxygen atom of aldehyde group).

The presence of the second EDG group (ester substituent) usually has a similar influence as the addition of 

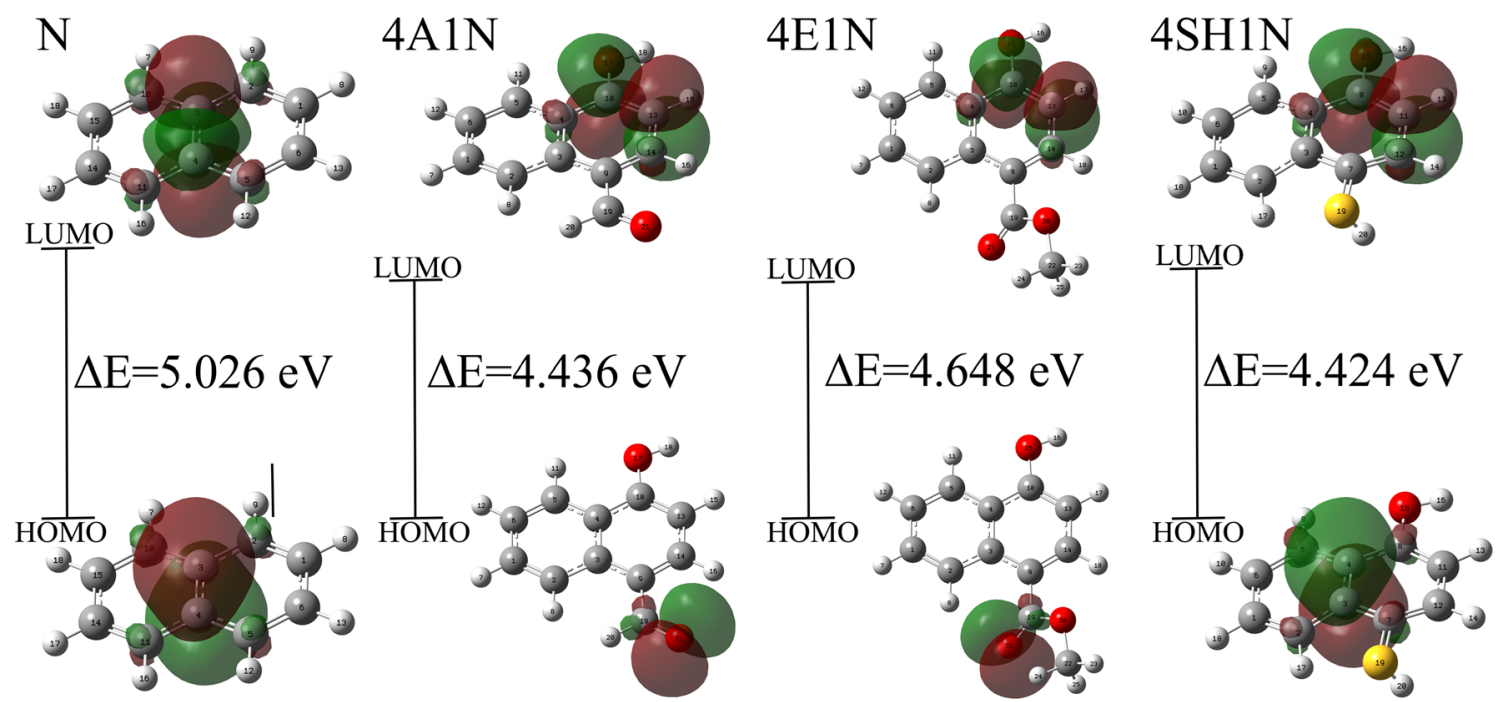

Fig. 5 The frontier orbitals of naphthalene and selected 1-naphthol derivatives calculated with NBO method

EWG: here, the charge transfer follows from the hydroxyl group to the oxygen atom of the second substituent. The only difference is made by the place of substitution resulting in the reactivity of the structure (the comparison of both substituents and their MEPs is presented in Fig. S1b). The most reactive is the $2 \mathrm{E} 1 \mathrm{~N}$ molecule: the nucleophilic center is localized on the methyl group and the naphthalene ring is the most electronegatively charged region. On the other hand, the least reactive is the $5 \mathrm{E} 1 \mathrm{~N}$ molecule: the situation is very similar to $4 \mathrm{~A} 1 \mathrm{~N}$. The reactivity order for both types of groups (based on the results shown in Table 1) is presented below:

$8 \mathrm{~A}>7 \mathrm{~A}>6 \mathrm{~A}>5 \mathrm{~A}>2 \mathrm{~A}>3 \mathrm{~A}>4 \mathrm{~A}$

$2 \mathrm{E}>7 \mathrm{E}>3 \mathrm{E}>4 \mathrm{E}>6 \mathrm{E}>8 \mathrm{E}>5 \mathrm{E}$

for the EWG and EDG groups respectively. It can be summarized that, firstly, the addition of the EWG substituent causes an increase of reactivity in relation to EDG

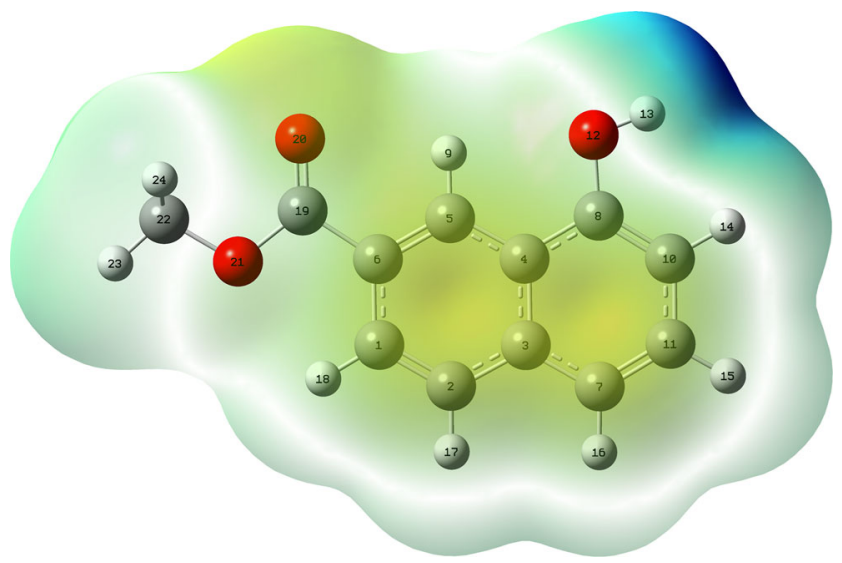

Fig. 6 The molecular electrostatic potential (MEP) calculated for 7E1N molecule substituents and, secondly, the highest reactivity is observed for molecules for which there is a possibility of $\mathrm{O}-\mathrm{H}-\mathrm{O}$ weak interactions formation (as in $7 \mathrm{~A} 1 \mathrm{~N}, 8 \mathrm{~A} 1 \mathrm{~N}$ and $2 \mathrm{E} 1 \mathrm{~N}$, 3E1N, 7E1N molecules).

Global reactivity descriptors The global reactivity descriptors like ionization energy, electron affinity, global hardness and softness, and electronegativity and electrophilicity index describe the properties of a molecule as a whole [60].

Their detailed analysis as well as some useful definitions can be found in SI.

One look at the overview of the global reactivity descriptors will show that the order of molecules when ordered according to different global reactivity descriptor is inconsistent, e.g., for $\eta$ the most reactive is a molecule with a substituent in the position 8 (for both tested types of electron-directing groups) while for $\omega$ the most reactive are $5 \mathrm{~A} 1 \mathrm{~N} / 6 \mathrm{E} 1 \mathrm{~N}$ molecules (see page A17 in SI). However, the observed situation is not unique. In literature, there are cases, in which the order of reactivity according to different descriptors is generally consistent (e.g., $\mu, \chi, S, \omega$ in Table 4 in [7]), but the vast majority of papers also reports different sequences of reactivity of studied molecules, which depends on tested descriptors (like in [12, $38,53,55,64,67])$. More detailed research shows that both variants are natural-it was shown in [46] the reactivity order based on global reactivity descriptors obtained from experimental values for atoms could be very similar during the analysis of certain parameters set, e.g., $\chi, \eta$ for $\mathrm{Li}, \mathrm{Na}$, $\mathrm{Al}$ atoms shown in Table 1 in [46] or differs significantly when another set of parameters is chosen (e.g., $I, A, \chi$ for $\mathrm{Li}, \mathrm{Na}, \mathrm{Al})$.

After summarizing all the descriptors of global reactivity (see Table 1; full data is presented in the Table S6), 
it was found that the most reactive are structures with EWG when charges are transferred through the whole molecule and accumulated in the second benzene ring, whereas the least reactive when charges are accumulated near each other in the same benzene ring as the hydroxyl group. For EDG structures, there is no such tendency to be found. It can be generalized that the most reactive molecules have substituents in the position 7 (and $5 / 2$ for EWG/EDG respectively) whereas the least reactive ones are the molecules with substituents attached to the first benzene ring (with hydroxyl group)/second benzene ring (2A1N, $3 \mathrm{~A} 1 \mathrm{~N}, 4 \mathrm{~A} 1 \mathrm{~N}$ and $8 \mathrm{~A} 1 \mathrm{~N} / 4 \mathrm{E} 1 \mathrm{~N}, 5 \mathrm{E} 1 \mathrm{~N}, 6 \mathrm{E} 1 \mathrm{~N}$, and $8 \mathrm{E} 1 \mathrm{~N}$ ) for EWG/EDG respectively.

It is showed from the table that the order of the most reactive molecules is as follows:

$7 \mathrm{~A}>5 \mathrm{~A}>8 \mathrm{~A}>2 \mathrm{~A}=4 \mathrm{~A}>3 \mathrm{~A}=6 \mathrm{~A}$

$2 \mathrm{E}>7 \mathrm{E}>4 \mathrm{E}>3 \mathrm{E}=6 \mathrm{E}=8 \mathrm{E}>5 \mathrm{E}$

And the order of the least reactive molecules:

$2 \mathrm{~A}=3 \mathrm{~A}=4 \mathrm{~A}>8 \mathrm{~A}>5 \mathrm{~A}=6 \mathrm{~A}=7 \mathrm{~A}$

$8 \mathrm{E}>5 \mathrm{E}>4 \mathrm{E}=6 \mathrm{E}>2 \mathrm{E}=3 \mathrm{E}=7 \mathrm{E}$

The substituent in position 4 regardless of the electrondirecting group is found to be the most nucleophilic center. For 1-naphthol derivatives with EWG, the most electrophilic are substituents in the positions 5 and 7 (ortho and para positions in the second benzene ring), whereas for EDG substituents with the meta positions 3 and 6 .

Local reactivity descriptors While global descriptors are related to the reactivity of chemical systems, local descriptors are related to the concept of selectivity. The key concepts in selectivity are the Fukui functions and the local softness. Unfortunately, the descriptors are not always able to identify unequivocally the specific sites where a reaction is favored or cannot take place [41]. Thereby, as the local reactivity descriptors, both the Fukui functions [66] and local softness were chosen as well as the descriptors derived from them: relative electrophilicity $s^{+} / s^{-}$and relative nucleophilicity $s^{-} / s^{+}$[51], $\Delta f_{k}$ and $\Delta s_{k}$ dual descriptors.

Due to the fact Fukui functions (and as the consequence the relative electrophilicity and relative nucleophilicity descriptors) are determined based on atom charges calculated using population analysis, the accuracy of the values of the local descriptors will depend not only on the accuracy of the calculation method but also on the selection of proper population analysis [26]. All the calculations were performed using NBO population analysis as giving realistic charge distribution [33].

Our results (presented in the Tables 2, S7, and S8 and as a more detailed description of each type of Fukui function in SI) indicate there is no similarity of reactive sites among tested local descriptors even though within the molecule the relative values of the Fukui function and local softness provide the same information. It means that the place, where the Fukui function is large, is very soft, whereas small values of the Fukui function imply hard regions [37].

The calculated values of different local descriptors are usually in no accordance, which was illustrated in Table 2. However, the situation is not unique. It was shown in [37] that it can happen that although the softest atom is, in general, the most reactive site of the molecule, there may be the other sites with smaller values of softness, that may become the most reactive sites, depending on the softness of the reacting molecule of the nucleophile/electrophile.

The picture of reactivity formed with Fukui functions is consistent with the expectations: when an electron is taken from the system, the most reactive are electron-rich places: hydrogen atoms, $\mathrm{H}^{O H}$; when an electron is added to the molecule, the atom reactivity is focused on $\mathrm{O}^{O H}$ and carbon atoms in the ortho positions in relation to the hydroxyl group to replenish partly positive charges on the atoms resulting from the EDG effect of the hydroxyl group.

The analysis of the relative electrophilicity and nucleophilicity is based on the following condition: the site having the highest $s_{k}^{+} / s_{k}^{-}$is the most probable site to be attacked by a nucleophile, and the site having the highest $s_{k}^{-} / s_{k}^{+}$ratio is the most probable site to be attacked by an electrophile [51].

The trend obtained from the results of $s_{k}^{+} / s_{k}^{-}$and $s_{k}^{-} / s_{k}^{+}$ (shown in Tables 2, S9, S10 and their analysis performed in SI) seems to be acceptable; however, the high reactivity of the positions 9 and 10 (as it is presented in Table 2) is not much trustworthy from the chemical point of view. The places are not reactive in the naphthalene ring; hence, the only explanation of the results could be the high mobility of electrons, which are instantaneously transferred from the places to the neighboring atoms due to the steric hindrance of carbon atoms forming naphthalene ring.

The analysis of dual descriptors $\Delta f$ and $\Delta s$ (for the calculation method, see Eqs. 8 and 9) is quite simple due to the order of atoms in substituted naphthols, arranged from the most electrophilic to the most nucleophilic. The results (presented in the Tables 2, S11 and the corresponding detailed description in SI) are very similar-there are only small differences in the order of atoms, not affecting the general picture of reactivity, thereby both descriptors will be analyzed at the same time (full analysis data is presented in Table S11).

The results are in good accordance with Fukui functions, thereby both the dual descriptors as well as Fukui functions can be used to predict the reactivity of a molecule which is consistent with the chemical expectations. Our calculations cannot confirm results presented in [50] that softness (and 
<smiles>[B]Oc1cccc2c(C([O])=O)cccc12</smiles><smiles>[O-][18O]c1cccc2c([18O])cccc12</smiles>

Fig. 7 The analysis of studied local descriptors for both tested types of electron-directing groups: for each pair on the left is EWG and on the right is EDG. The position of substituents is arbitrary and shown

not Fukui functions) should be a better descriptor of the reactivity.

The picture obtained from all local descriptors calculations is coherent and it predicts that the derivatives with EWG have structures (as it can be seen in Fig. 7), in which both substituents affect the polarity of the molecule. Following the concept of electron donation as the crucial mechanism for anti-corrosion properties [42], it is clear that the 1-naphthol derivatives with EWG substituents can inhibit corrosion due to the ability of such system to donate electrons (to neutralize radical species) and at the same time the presence of delocalized electrons from naphthalene ring stabilizes the molecule. Additionally, the second substituent (hydroxyl group) can behave as a shield protecting the system against electrons from the external medium.

As it is seen from Fig. 7 and data in Table 2, the substituted 1-naphthols may be anti-corrosion useful even in the case of surfaces with electron excess. The additional functionality of such structures is that they have also electrophilic centers so it is a way to bond them to the surface of interest and decrease its reactivity.
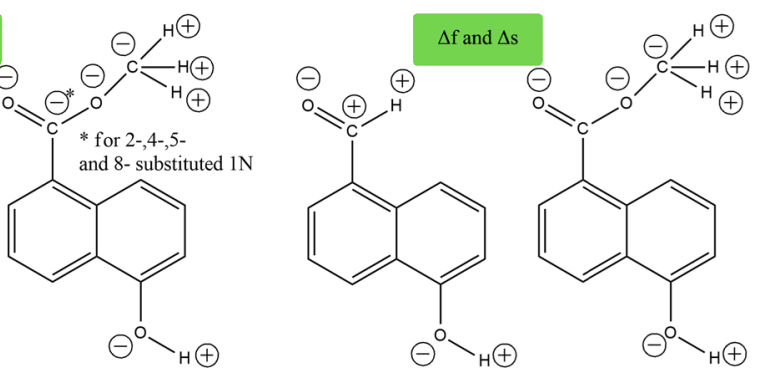

for a 5-substituted 1-naphthol molecule. The electrophilic/nucleophilic center is presented as $+/-$ in a circle respectively

\section{NLO properties}

The values of dipole moments, static and dynamic polarizability, and first and second-order hyperpolarizability tensors for tested compounds are listed in Table 3 (full data is collected in Table S12 as well as more detailed analysis of the NLO properties presented in SI).

Generally, the best positions for high polarization (indicated by dipole moment values) are 5 and 6 providing a large distance between both substituents, whereas for low polarization good choice is position 2 (two neighboring positions in the same benzene ring).

In the matter of the thio derivatives, the values are extremely high for the compounds having a substituent in the positions 4 and 5 (more than 44 Debye, which is $25 \%$ more than calculated for single DAST molecule [45]) and quite big for the position 6 of the aromatic ring.

The values of static and dynamic NLO properties are comparable and the dynamic ones are always slightly larger (the exception are thiol derivatives). Thereby, the analysis will be performed for the static case. The visual overview

Table 3 The NLO parameters of selected molecules; the dipole moment expressed in Debye, the polarizability and hyperpolarizability tensors in ESU units; values for $\alpha, \beta$, and $\gamma$ should be multiplied by $10^{-24}, 10^{-30}$, and $10^{-36}$ respectively

\begin{tabular}{|c|c|c|c|c|c|c|c|c|c|c|}
\hline \multirow[b]{2}{*}{ Compound } & \multirow[b]{2}{*}{$\mu$} & \multirow[b]{2}{*}{$\mu_{x}$} & \multirow[b]{2}{*}{$\mu_{y}$} & \multirow[b]{2}{*}{$\mu_{z}$} & \multicolumn{3}{|l|}{ Static } & \multicolumn{3}{|c|}{ Dynamic for $532 \mathrm{~nm}$} \\
\hline & & & & & $\alpha$ & $\beta$ & $\gamma$ & $\alpha$ & $\beta$ & $\gamma$ \\
\hline $\mathrm{N}$ & 0.000 & 0.000 & 0.000 & 0.000 & 15.894 & 0.000 & 1.814 & 16.930 & 0.000 & 2.741 \\
\hline $1 \mathrm{~N}$ & 1.610 & -1.357 & 0.866 & 0.000 & 16.697 & 1.248 & 2.125 & 17.891 & 2.148 & 3.547 \\
\hline $3 \mathrm{~A} 1 \mathrm{~N}$ & 1.806 & -0.243 & 1.789 & 0.000 & 19.499 & 4.143 & 6.920 & 21.263 & 8.226 & 16.063 \\
\hline $6 \mathrm{~A} 1 \mathrm{~N}$ & 3.488 & 1.560 & 3.119 & 0.000 & 19.494 & 5.718 & 7.554 & 21.211 & 12.433 & 20.812 \\
\hline $7 \mathrm{~A} 1 \mathrm{~N}$ & 2.514 & -0.807 & 2.381 & 0.000 & 19.477 & 5.774 & 7.294 & 21.278 & 12.663 & 17.276 \\
\hline $8 \mathrm{~A} 1 \mathrm{~N}$ & 2.126 & 1.863 & -0.977 & 0.307 & 18.839 & 1.159 & 3.636 & 20.309 & 2.885 & 7.660 \\
\hline $2 \mathrm{E} 1 \mathrm{~N}$ & 2.230 & -1.302 & 1.810 & 0.000 & 22.303 & 2.989 & 7.161 & 24.201 & 4.266 & 13.223 \\
\hline $5 \mathrm{E} 1 \mathrm{~N}$ & 3.974 & -3.481 & -0.031 & 1.916 & 20.868 & 0.850 & 3.498 & 22.272 & 1.869 & 6.556 \\
\hline $7 \mathrm{E} 1 \mathrm{~N}$ & 1.078 & -1.010 & 0.375 & 0.000 & 22.262 & 4.398 & 10.338 & 24.081 & 9.067 & 20.362 \\
\hline $8 \mathrm{E} 1 \mathrm{~N}$ & 2.583 & -1.598 & -1.180 & 1.651 & 20.806 & 1.969 & 3.227 & 22.176 & 3.277 & 5.957 \\
\hline
\end{tabular}


of the NLO activity of each position in the aromatic ring is presented in Fig. 8.

In all the cases, structures having substituents at positions 5 and 8 lead to the least NLO active molecules while the positions 7 (both types) and 3,6/2,4 (EWG/EDG respectively) lead to the most NLO active compounds.

The values of $\alpha$ for EWG are maximally $17 \%$ greater than in unsubstituted $1 \mathrm{~N}$, whereas for EDG is $34 \%$ respectively. It is worth to note that the smallest value for EDG is about $7 \%$ bigger than the greatest value for EWG. For both groups, the maximal values are obtained when the substituent is in the same benzene ring as the hydroxyl group while the minimal values are found for the substituent in the second benzene ring at the same position as the $\mathrm{OH}$ group.

While alpha values are at a comparable level, beta values are strictly associated with the position and type of
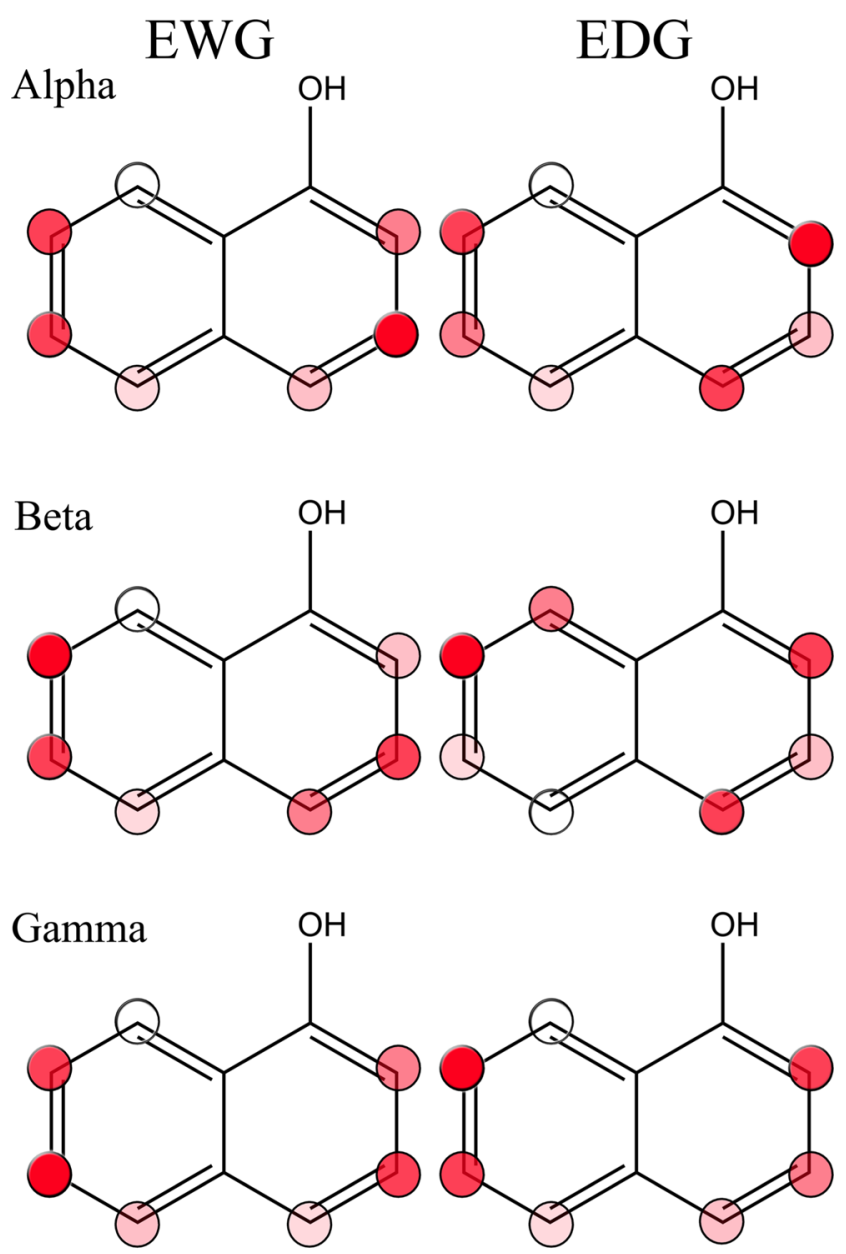

The order of NLO activity

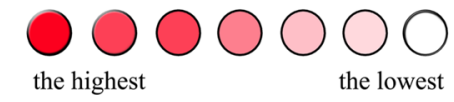

Fig. 8 Correlation between the substitution position and the value of the polarizability and hyperpolarizability tensors
Table 4 The calculated lowest (on the left) and highest (on the right) values of tested NLO properties for each group having a moderate magnitude of electron-directing effect in relation to the urea molecule (the values for the urea are taken as $100 \%$ )

\begin{tabular}{lllll}
\hline & EWG & \multicolumn{3}{c}{ EDG } \\
\hline$\mu$ & $-33 \%$ & $+32 \%$ & $-61 \%$ & $+45 \%$ \\
$\alpha$ & $+414 \%$ & $+432 \%$ & $+468 \%$ & $+509 \%$ \\
$\beta$ & $+555 \%$ & $+3162 \%$ & $+380 \%$ & $+2385 \%$ \\
$\gamma$ & $+2231 \%$ & $+4742 \%$ & $+1969 \%$ & $+6527 \%$ \\
\hline
\end{tabular}

substituent. For EWG, the values are more than 2.4 times bigger than in $1 \mathrm{~N}$ (the exception is the $8 \mathrm{~A} 1 \mathrm{~N}$ molecule, whose value is slightly less than in $1 \mathrm{~N}$ ). For EDG, the values are also greater than in $1 \mathrm{~N}$ (with the exception for $5 \mathrm{E} 1 \mathrm{~N}$ ), but smaller than for EWG.

Gamma value increases with the presence of additional substituents: the addition of $\mathrm{OH}$ group increases its NLO behavior more than $15 \%$, and further substitution improves the second-order hyperpolarizability value more than 70/50\% for EWG/EDG groups respectively. The maximal and minimal values of gamma can be found, as in the case of beta, for the second benzene ring positions.

Generally, among all tested monosubstituted 1-naphthol derivatives, there is no one position giving the best results of all NLO properties. Analysis for each position shows that for almost all positions the finest values are obtained for the EDG, the exceptions are positions 4 and 7 . The comparison with values calculated using the same method for the urea molecule having $C_{2}$ point group symmetry presented in Table 4 shows more than 5/6 times larger values of alpha, 32/24 times larger values of beta, and 48/66 times larger values of gamma for EWG/EDG respectively. For $532 \mathrm{~nm}$ (dynamic case), the results are enhanced even more: $\alpha 6 / 7, \beta$ $61 / 144, \gamma$ 119/116 times larger (EWG/EDG) when referring to the urea molecule.

\section{Conclusions}

In summary, the detailed theoretical analysis concerning 1-naphthol derivatives differing in substituent type and its position in the naphthalene ring was performed.

Calculations with APF-D/NLO-V method showed the thio derivatives of 1-naphthol can exist only for the positions 4,5 , and 6 of the aromatic ring; the other structures are not possible due to the strong repulsion of electrons from both substituents. According to expectations, electrondirecting groups have a substantial contribution to the obtained geometry (bond lengths, valence angles). EDG has a crucial influence on the stability of molecules (energetic relations and $\left.E_{\text {gap }}\right)$; it was found that more stable are molecules having a substituent in the same benzene ring 
as the hydroxyl group; for the same substituent position, higher values of $E_{\text {gap }}$ are given by EDG rather than EWG. Calculations reveal that for the molecules with substituents in positions 7 and 8 (and 2E1N), there is a possibility of forming intramolecular O-H-O interactions, which was indicated by energetic relations between isomers, MEP, and global reactivity descriptors.

The IR spectra were simulated for all studied compounds and the vibrations are in accordance with the literature.

The most reactive structures with EWG are molecules in which charges are transferred through the whole molecule and accumulated in the second benzene ring, whereas the least reactive when charges are accumulated near each other in the same benzene ring as the hydroxyl group. For EDG structures, there is no such tendency to be found. The most reactive molecules have substituents in position 7 (and 5/2 for EWG/EDG respectively), whereas the least reactive are molecules with substituents attached to the first benzene ring (with hydroxyl group)/second benzene ring for EWG/EDG respectively. Global reactivity descriptors analysis confirm that conclusion: it is seen the least reactive are molecules with the possibility of more regular electron distribution occurrence when EDG is a substituent whereas for EWG as a substituent when the substituents are localized as close as it is possible. The study of local reactivity descriptors showed that all the tested compounds do not exhibit radical character; the carbon atoms of naphthalene and oxygen atoms are nucleophilic sites, whereas hydrogen atoms and $\mathrm{C} 1$ carbon atom are electrophilic ones. The picture of reactivity generally (the exception is $s^{+} / s^{-}$and $\left.s^{-} / s^{+}\right)$is consistent with expectations.

1-Naphthol derivatives having EWG as substituent could be effective low-cost anti-corrosion materials. The high stability of the aromatic structure coupled with the polarity of the molecule provided by a different type of substituents allows for permanent connection with a surface to be protected and the reduction of its reactivity.

The addition of the second substituent to 1-naphthol improves the NLO properties. The most NLO active are molecules with a substituent in position 7, the least in the positions 5 and 8 . Greater values of polarizability tensors are observed for almost all positions of naphthalene ring for compounds having EDG in comparison to molecules with EWG; the first-order hyperpolarizability tensor values are bigger when EWG is used as the substituent.

The hyperpolarizability tensors obtained for all substituted naphthols are much greater than in the urea moleculethey are even sixty times greater for the static case; for the dynamic case, values of hyperpolarizability tensors for some substituents are over a hundred times greater.

It means that substituted naphthols may be considered as very good materials for NLO devices and anticorrosion protection. They are chemically stable and, what is important from the practical point of view, not expensive. They are also easy to be used in polymer composite preparation; hence, they could be used as effective components of multifunctional material systems.

Supplementary Information The online version contains supplementary material available at (https://doi.org/10.1007/s11224-02001674-x).

Funding The calculations have been carried out using resources provided by Wroclaw Centre for Networking and Supercomputing (http://wcss.pl), grant No. 10138675.

Data availability The datasets generated during and/or analyzed during the current study are available from the corresponding author on reasonable request.

Author contributions All authors contributed to the study conception and design. Material preparation, data collection, and analysis were performed by Ilona Radkowska (I. Radkowska) and Piotr Bragiel (P. Bragiel). The first draft of the manuscript was written by I. Radkowska and all authors commented on previous versions of the manuscript. All authors read and approved the final manuscript.

\section{Compliance with ethical standards}

Conflict of interest The authors declare that they have no conflict of interest.

Open Access This article is licensed under a Creative Commons Attribution 4.0 International License, which permits use, sharing, adaptation, distribution and reproduction in any medium or format, as long as you give appropriate credit to the original author(s) and the source, provide a link to the Creative Commons licence, and indicate if changes were made. The images or other third party material in this article are included in the article's Creative Commons licence, unless indicated otherwise in a credit line to the material. If material is not included in the article's Creative Commons licence and your intended use is not permitted by statutory regulation or exceeds the permitted use, you will need to obtain permission directly from the copyright holder. To view a copy of this licence, visit http:// creativecommonshorg/licenses/by/4.0/.

\section{References}

1. Meneguzzi A, Ferreira C, Pham M, Delamar M, Lacaze P (1999) Electrochemical synthesis and characterization of poly(5-amino1-naphthol) on mild steel electrodes for corrosion protection. Electrochim Acta 44(12):2149-2156. https://doi.org/10.1016/ S0013-4686(98)00323-5. http://www.sciencedirect.com/science/ article/pii/S0013468698003235

2. Ji Aihara (1999) Reduced HOMO-LUMO gap as an index of kinetic stability for polycyclic aromatic hydrocarbons. J Phys Chem A 103(37):7487-7495. https://doi.org/10.1021/jp990092i

3. Amiri SS, Makarem S, Ahmar H, Ashenagar S (2016) Theoretical studies and spectroscopic characterization of novel 4-methyl-5-((5-phenyl-1,3,4-oxadiazol-2-yl)thio)benzene-1,2diol. J Mol Struct 1119:18-24. https://doi.org/10.1016/j.molstruc. 2016.04.053. http://www.sciencedirect.com/science/article/pii/ S0022286016303763 
4. Austin A, Petersson GA, Frisch MJ, Dobek FJ, Scalmani G, Throssell K (2012) A density functional with spherical atom dispersion terms. J Chem Theory Comput 8(12):4989-5007. https://doi.org/10.1021/ct300778e. pMID: 26593191

5. Bamoniri A, Pourali AR, Nazifi SMR (2013) Facile synthesis of 1-naphthol azo dyes with nano siO2/HIO4 under solvent-free conditions. Bull Chem Soc Ethiop 27(3):439-445

6. Bamoniri A, Mirjalili BBF, Moshtael-Arani N (2014) Environmentally green approach to synthesize azo dyes based on 1naphthol using nano BF3 siO2 under solvent-free conditions. Green Chemistry Letters and Reviews 7(4):393-403

7. Bendjeddou A, Abbaz T, Gouasmia A, Villemin D (2016) Molecular structure, HOMO-LUMO, MEP and fukui function analysis of some TTF-donor substituted molecules using DFT (B3LYP) calculations. International Research Journal of Pure and Applied Chemistry 1-9

8. Bragiel P, Radkowska I, Belka R, Marciniak B, Bak Z (2018) Structural, spectroscopic and NLO features of the 4-chloro1-naphthol. J Mol Struct 1154:27-38. https://doi.org/10.1016/ j.molstruc.2017.10.017. https://www.sciencedirect.com/science/ article/abs/pii/S0022286017313480

9. Burgos WD, Berry DF, Bhandari A, Novak JT (1999) Impact of soil-chemical interactions on the bioavailability of naphthalene and 1-naphthol. Water Res 33(18):3789-3795. https://doi.org/ 10.1016/S0043-1354(99)00098-6. http://www.sciencedirect.com/ science/article/pii/S0043135499000986

10. Chaitanya K, Santhamma C, Prasad K, Veeraiah V (2012) Molecular structure, vibrational spectroscopic (ft-ir, ft-raman), first order hyperpolarizability, NBO analysis, HOMO and LUMO analysis, thermodynamic properties of 3,5-dimethylbenzophenone by ab inito $\mathrm{HF}$ and density functional method. Journal of Atomic and Molecular Sciences 3(1):1-22

11. Chao Y, Chang M, Chang C (1998) Water-repellent acid dyes: the influence of the perfluorobutamido group on the colour, dyeing and fastness properties of 2-(p-alkyl) phenylazo-1-naphthol acid dyes. Dye Pigment 39(3):183-191

12. Chattaraj PK, Duley S (2010) Electron affinity, electronegativity, and electrophilicity of atoms and ions. Journal of Chemical \& Engineering Data 55(5):1882-1886. https://doi.org/10.1021/ je900892p

13. Cheng KL (1954) Spectropotometric determination of palladium with 2-nitroso-1-naphthol. Anal Chem 26(12):1894-1895

14. Chillara V, Headings L, Dapino M (2016) Multifunctional composites with intrinsic pressure actuation and prestress for morphing structures. Compos Struct 157:265-274. https://doi. org/10.1016/j.compstruct.2016.08.044. http://www.sciencedirect. com/science/article/pii/S0263822316305852

15. Clark L (1958) Cobalt determination in soils and rocks with 2-nitroso-1-naphthol. Anal Chem 30(6):1153-1156

16. Contreras RR, Fuentealba P, Galvan M, Perez P (1999) A direct evaluation of regional fukui functions in molecules. Chem Phys Lett 304(5-6):405-413

17. Costa JC, Taveira RJ, Lima CF, Mendes A, Santos LM (2016) Optical band gaps of organic semiconductor materials. Opt Mater 58:51-60. https://doi.org/10.1016/j.optmat.2016.03.041. http:// www.sciencedirect.com/science/article/pii/S0925346716301483

18. Crossley DL, Gabbutt CD, Heron BM, Kay P, Mogstad M (2012) Synthesis and photochromic properties of spiro (naphthopyran-7' h-benzocyclohepta-5', 8'-dienes). Dye Pigment 95(1):62-68

19. Demircioglu Z, Ersanli CC, Kantar GK, Sasmaz S (2019) Spectroscopic, hirshfeld surface, $\mathrm{x}$-ray diffraction methodologies and local and global chemical activity calculations of 5-(2methoxy-4-(prop-1-en-1-yl)phenoxy)pyrazine-2,3-dicarbonitrile. J Mol Struct 1181:25-37. https://doi.org/10.1016/j.molstruc. 2018.12.072. http://www.sciencedirect.com/science/article/pii/ S0022286018315059
20. Frisch MJ, Trucks GW, Schlegel HB, Scuseria GE, Robb MA, Cheeseman JR, Scalmani G, Barone V, Petersson GA, Nakatsuji $\mathrm{H}$, Li X, Caricato M, Marenich AV, Bloino J, Janesko BG, Gomperts R, Mennucci B, Hratchian HP, Ortiz JV, Izmaylov AF, Sonnenberg JL, Williams-Young D, Ding F, Lipparini F, Egidi F, Goings J, Peng B, Petrone A, Henderson T, Ranasinghe D, Zakrzewski VG, Gao J, Rega N, Zheng G, Liang W, Hada M, Ehara M, Toyota K, Fukuda R, Hasegawa J, Ishida M, Nakajima T, Honda Y, Kitao O, Nakai H, Vreven T, Throssell K, Montgomery JAJr, Peralta JE, Ogliaro F, Bearpark MJ, Heyd JJ, Brothers EN, Kudin KN, Staroverov VN, Keith TA, Kobayashi R, Normand J, Raghavachari K, Rendell AP, Burant JC, Iyengar SS, Tomasi J, Cossi M, Millam JM, Klene M, Adamo C, Cammi R, Ochterski JW, Martin RL, Morokuma K, Farkas O, Foresman JB, Fox DJ (2016) Gaussian 16 revision a.03. Gaussian inc. Wallingford CT

21. Gazquez JL, Mendez F (1994) The hard and soft acids and bases principle an atoms in molecules viewpoint. J Phys Chem 98(17):4591-4593

22. Glendening ED, Reed AE, Carpenter JE, Weinhold F (1998) NBO 3.1. Used As the part of the gaussian2016 - as link 607

23. Hasan M, Zhao J, Jiang Z (2019) Micromanufacturing of composite materials: a review. International Journal of Extreme Manufacturing 1(1):012004

24. Hatua K, Nandi PK (2014) Double coned inverse sandwich complexes [M- $\left(\eta^{4}-c_{4} h_{4}\right)$-M of Gr-IA and Gr-IIA metals: theoretical study of electronic of structure and second hyperpolarizability. J Mol Model 20(9):2440:1-10. https://doi.org/10.1007/s00894014-2440-0

25. Huang X, Zhao G, Liu M, Li F, Qiao J, Zhao S (2012) Highly sensitive electrochemical determination of 1-naphthol based on highindex facet $\mathrm{snO} 2$ modified electrode. Electrochim Acta 83:478484. https://doi.org/10.1016/j.electacta.2012.08.008. http://www. sciencedirect.com/science/article/pii/S0013468612012820

26. Huizar LHM, Rios-Reyes CH, Olvera-Maturano NJ, Robles J, Rodriguez JA (2015) Chemical reactivity of quinclorac employing the HSAB local principle - fukui function. Open Chemistry 13:52-60. https://doi.org/10.1515/chem-2015-0008. https://www. degruyter.com/view/j/chem.2015.13.issue-1/chem-2015-0008/ chem-2015-0008.xml

27. Krygowski TM, Ejsmont K, Stepien BT, Cyranski MK, Poater J, Solà M (2004) Relation between the substituent effect and aromaticity. J Org Chem 69(20):6634-6640. https://doi.org/10. 1021/jo0492113. pMID: 15387585

28. Lang PF, Smith BC (2003) Ionization energies of atoms and atomic ions. J Chem Educ 80(8):938. https://doi.org/10.1021/ ed080p938

29. Lim MI, Pan YG (1998) Hair dye compositions containing 2,3 dialkyl-4-aminophenol and a 2-alkyl-1-naphthol. US patent $5,849,042$

30. Long M, Trotter P (1981) Vibrational manifold considerations for the metal indicator dye 2-(2-pyridylazo)-1-naphthol. Appl Spectrosc 35(3):289-292

31. Luo SJ, Yang JT, Du WF, Laref A (2011) Mechanism of linear and nonlinear optical properties of the urea crystal family. J Phys Chem A 115(20):5192-5200. https://doi.org/10.1021/jp200164s. pMID: 21526856

32. Manning D, Menis O (1962) Spectrophotometric determination of ruthenium with 2-nitroso-1-naphthol. Anal Chem 34(1):9496

33. Mao JX (2014) Atomic charges in molecules: a classical concept in modern computational chemistry. Journal of Postdoctoral Research 2(2). http://www.postdocjournal.com/file_journal/673_ 22745370.pdf

34. Maphoru MV, Heveling J, Pillai SK (2014) Oxidative coupling of 1-naphthols over noble and base metal catalysts. ChemPlusChem 79(1):99-106. https://doi.org/10.1002/cplu.201300307 
35. Mashhadizadeh MH, Yousefi T, Golikand AN (2012) A nickel hexacyanoferrate and poly(1-naphthol) hybrid film modified electrode used in the selective electroanalysis of dopamine. Electrochim Acta 59:321-328. https://doi.org/10.1016/ j.electacta.2011.10.070. http://www.sciencedirect.com/science/ article/pii/S0013468611016227

36. Matsui M, Kobayashi K, Shibata K, Takase Y (1981) Ozonation of dyes. ii-ozone treatment of 4-phenylazo-1-naphthol. J Soc Dye Colour 97(5):210-213

37. Mendez F, Gazquez JL (1994) Chemical reactivity of enolate ions the local hard and soft acids and bases principle viewpoint. J Am Chem Soc 116(20):9298-9301

38. Mendoza-Huizar LH (2015) Global and local reactivity descriptors for picloram herbicide: a theoretical quantum study. Quimica Nova 38(1):71-76

39. Meunier M, Quirke N, Binesti D (1999) The calculation of the electron affinity of atoms and molecules. Mol Simul 23(2):109_ 125. https://doi.org/10.1080/08927029908022116

40. Miller BJ, Howard DL, Lane JR, Kjaergaard HG, Dunn ME, Vaida V (2009) SH-Stretching vibrational spectra of ethanethiol and tert-butylthiol. J Phys Chem A 113(26):75767583. https://doi.org/10.1021/jp9017162. pMID: 19432460

41. Morell C, Grand A, Toro-Labbe A (2005) New dual descriptor for chemical reactivity. J Phys Chem A 109(1):205-212. https://doi.org/10.1021/jp046577a. pMID: 16839107

42. Mydlova L, Kluza K, Halama M, Makowska-Janusik M (2019) Anti-corrosive surface effect of ascorbic acid caused on the zno nanoparticles - experimental and theoretical investigations. Appl Surf Sci 483:562-571. https://doi.org/10.1016/j.apsusc. 2019.03.324. http://www.sciencedirect.com/science/article/pii/ S0169433219309602

43. Narayana KJ, Burela RG (2018) A review of recent research on multifunctional composite materials and structures with their applications. Materials Today: Proceedings 5(2, Part 1):55805590. https://doi.org/10.1016/j.matpr.2017.12.149. 7th International Conference of Materials Processing and Characterization, March 17-19, 2017

44. Ohsaka T, Ohba M, Sato M, Oyama N, Tanaka S, Nakamura S (1991) Formation of a novel electroactive film by electropolymerization of 5-amino-1-naphthol. Journal of Electroanalytical Chemistry and Interfacial Electrochemistry 300(1):5166. https://doi.org/10.1016/0022-0728(91)85383-Z. http://www. sciencedirect.com/science/article/pii/002207289185383Z

45. Oikawa H, Fujita S, Kasai H, Okada S, Tripathy SK, Nakanishi H (2000) Electric field-induced orientation of organic microcrystals with large dipole moment in dispersion liquid. Colloids Surf A Physicochem Eng Asp 169(1-3):251-258

46. Parr RG, Pearson RG (1983) Absolute hardness companion parameter to absolute electronegativity. J Am Chem Soc 105(26):7512-7516

47. Paschoal D, Dos Santos HF (2013) Assessing the quantum mechanical level of theory for prediction of linear and nonlinear optical properties of push-pull organic molecules. J Mol Model 19(5):2079-2090. https://doi.org/10.1007/s00894-012-1644-4

48. Pritchard H, Skinner H (1955) The concept of electronegativity. Chem Rev 55(4):745-786

49. Reeves RL, Calabrese GS, Harkaway SA (1983) Kinetics and mechanism of chelation of nickel (ii) by 2-(2-pyridylazo)-1naphthol(alpha-PAN) dyes. Inorg Chem 22(21):3076-3084

50. Rodríguez-Zavala J (2019) Local reactivity through fukui function on endohedral mono-metallofullerenes. Physica E: Low-Dimensional Systems and Nanostructures 105:186195. https://doi.org/10.1016/j.physe.2018.08.027. http://www. sciencedirect.com/science/article/pii/S138694771830300X
51. Roy RK, Krishnamurti S, Geerlings P, Pal S (1998) Local softness and hardness based reactivity descriptors for predicting intra- and intermolecular reactivity sequences carbonyl compounds. J Phys Chem A 102(21):3746-3755. https://doi.org/10.1021/jp973450v

52. Saeed MU, Li BB, Chen ZF (2016) Mechanical effects of microchannels on fiber-reinforced composite structure. Compos Struct 154:129-141. https://doi.org/10.1016/j.compstruct. 2016.07.057. http://www.sciencedirect.com/science/article/pii/ S0263822316312818

53. Serdaroglu G, Sahin N (2019) The synthesis and characterization of 1-(allyl)-3-(2-methylbenzyl)benzimidazolium chloride FT-IR, NMR, and DFT computational investigation. J Mol Struct 1178:212-221. https://doi.org/10.1016/j.molstruc.2018.10.028. http://www.sciencedirect.com/science/article/pii/ S0022286018312134

54. Shah TB, Patel SB, Metha TB (2009) Synthesis, characterization and dyeing behavior of oligomeric trimethylolmelamine-1naphthol acid azo dyes. Int J Polym Mater 58(12):681-691

55. Shweta, Khan E, Prajapati $P$, Tandon $P$, Bharti $P$, Kumar $P$, Maurya R (2019) Structural reactivity analyses of a neoflavonoid 4-methoxydalbergione using vibrational spectroscopy and quantum chemical calculations. J Mol Struct 1175:28-38. https://doi.org/10.1016/j.molstruc.2018.07.075. http://www. sciencedirect.com/science/article/pii/S0022286018308949

56. Spoliti M, Pieretti A, Bencivenni L, Sanna N (1997) Theoretical study of the stable C2 and Cs symmetry isomers of urea. Electron J Theor Chem 2(1):149-159

57. Srivastava K, Shukla A, Karthick T, Velaga SP, Tandon P, Sinha K, Shimpi MR (2019) Molecular structure, spectroscopic signature and reactivity analyses of paracetamol hydrochloride monohydrate salt using density functional theory calculations. CrystEngComm 21:857-865. https://doi.org/10.1039/C8CE01761A

58. Suresh S, Arivuoli D (2012) Nanomaterials for nonlinear optical (NLO) applications: a review. Rev Adv Mater Sci 30(3):243253

59. Thandalam SK, Ramanathan S, Sundarrajan S (2015) Synthesis, microstructural and mechanical properties of ex situ zircon particles $(\mathrm{ZrSiO} 4)$ reinforced Metal Matrix Composites (MMCs): a review. Journal of Materials Research and Technology 4(3):333347

60. Torrent-Sucarrat M, De Proft F, Ayers P, Geerlings P (2010) On the applicability of local softness and hardness. Phys Chem Chem Phys 12(5):1072-1080

61. Uzun S, Esen Z, Koc E, Usta NC, Ceylan M (2019) Experimental and density functional theory (MEP, FMO, NLO, fukui functions) and antibacterial activity studies on 2-amino-4-(4-nitrophenyl)-5,6-dihydrobenzo $\mathrm{H}$ quinoline-3carbonitrile. J Mol Struct 1178:450-457. https://doi.org/10.1016/ j.molstruc.2018.10.001. http://www.sciencedirect.com/science/ article/pii/S0022286018311785

62. Valentini L, Bittolo Bon S, Signetti S, Pugno NM (2016) Graphene-based bionic composites with multifunctional and repairing properties. ACS Appl Mater Interfaces 8(12):76077612. https://doi.org/10.1021/acsami.6b02530. pMID: 26971362

63. Veeramanikandan S, Sherine HB, Dhandapani A, Subashchandrabose S (2019) Synthesis, solid state structure, hirshfeld surface, nonlinear optics and DFT studies on novel bischalcone derivative. J Mol Struct 1180:798-811. https://doi.org/10.1016/ j.molstruc.2018.12.045. http://www.sciencedirect.com/science/ article/pii/S0022286018314728

64. Vijayaraj R, Subramanian V, Chattaraj P (2009) Comparison of global reactivity descriptors calculated using various density functionals: a QSAR perspective. J Chem Theory Comput 5(10):2744-2753 
65. Xiao Y, Qiao W, Fukuda H, Hatta H (2016) The effect of embedded devices on structural integrity of composite laminates. Compos Struct 153:21-29

66. Yang W, Parr RG (1985) Hardness, softness, and the fukui function in the electronic theory of metals and catalysis. Proc Natl Acad Sci 82(20):6723-6726. https://doi.org/10.1073/pnas.82. 20.6723
67. Zhan CG, Nichols JA, Dixon DA (2003) Ionization potential, electron affinity, electronegativity, hardness, and electron excitation energy molecular properties from density functional theory orbital energies. J Phys Chem A 107(20):4184-4195. https://doi.org/10.1021/jp0225774

Publisher's note Springer Nature remains neutral with regard to jurisdictional claims in published maps and institutional affiliations. 